\title{
Vision Information and Consumer's Purchasing Behaviors
}

\author{
Yousuke SANBAYASHI', Toshio UENO ${ }^{\AA}$, Mitsuyuki KAWAKAMI \\ and Takao OHKUBO ${ }^{c}$ \\ ${ }^{\wedge}$ Faculty of Engineering Kanagawa University \\ ${ }^{8}$ Tokyo Metropolitan Institute of Technology \\ 'College of Industrial Technology Nihon University
}

\section{Introduction}

Peaple'a in store product purchasing activities are complexly influenced by awide variety of factors. Factors of the shopping environment, such as the store, display, day of the week, time of day, temperature, and advertising, as well as quality factors, such as product attributes, function, and price, all combine with the information and needs of the buyer, their preferences, financial situation, and psychological state. The sensory processes that occur when the consumer actually sees and touches a product are therefore very important. The consumer processes information obtained from their primary sense, vision, and their decision to buy is the ultimate output of that processing.

This study addresses several elements of the environmental factors that influence consumers when they see a product, and examines their impact on salability. By equipping consumers with an eyeball movement tracking device and monitoring their shopping activities in an actual store, researchers were able to identify how the consumer obtains information from the environmental elements listed above that influence their purchasing practices. We also examined the way consumers perceive products, regard the actual appearance, and make purchasing decisions.

\section{Research Methods}

2-1 Analysis of Purchasing Practices and Environmental Factors

To identify the impact of various elements, particularly product placement, on purchasing practices, we performed a Type 1 Quantification analysis using the sales volumes of each item in Bakery for one month as the dependent variable, and the product display location, shelf height, facing, display placement, and existence of POP (point of purchase) as the independent variables. The number of categories for each item were $3,4,2,2$, and 2 , respectively. The product placement and POP information were changed weekly, and sales performance data was collected on a similar basis.

\section{2-2 Experiment}

Subjects were asked to purchase pastries at this bakery, and were equipped with an eye mark recorder (EMR-8, NAC) while shopping to allow researchers to monitor their line of sight. Their purchasing behaviors were also recorded on a video camera, and their line of movement and purchasing performance were monitored. The subjects were four mentally and physically healthy women who had not visited this bakery before. When purchasing their items, the subjects were instructed to make their purchases based only on the average price of goods in that shop.

\section{Results and Analysis}

The results of the Type 1 Quantification analysis indicated a multiple correlation coefficient of $R=0.758$ and acoefficient of determination of 0.57 , indicating that the model explains the variability well. The single correlation coefficient of each item indicates that the 
importance of the environmental elements increases in the following order: product display location, height, POP, facing, display location. That is, the purchase of a product is most hevilty influenced by the product display location and the display level, while the impact of the width of the display (facing) and the display placement on each shelf was small. The results of the category score showed that there was a tendency for salability to be dependent on the product display location within the store, and that the product display level has an impact on purchases in that items placed on the 2nd and 3rd shelves may have a greatly increased likelifood of sale compared to other locations.

The results of this experiment were used to consider the relationship between various factors and elements identified here as having an impact on purchasing becision, with actual purchasing behaviors. The attention level distribution among the subjects in the store as recorded by their eye cameras is shown in Figure 1 . These results are highly consistent with the hypothesis that product level has a positive impact on salability. When the subjects were moving about the shop, they looked around horizontally, but when they were standing still, they moved their heads vertically. Whether standing still or moving, it is possible to predict that the product displays at a level where visual information can be easily obtained can influence purchasing decisions. The attention point levels based on differences in position within the store are shown in Figure 2. No statistically significant differences were found.

We defined a cluster of consecutive attention points where the largest fixation range was 2 and the minimum fixation time was $100 \mathrm{msec}$. as one fixation point, and recorded the fixation time. The distribution of the average fixation time and fixation frequency for purchases of randomly selected products is evident from the figures, the products with the larger salability tend to have a large fixation frequency, but the salability is not related to fixation time.

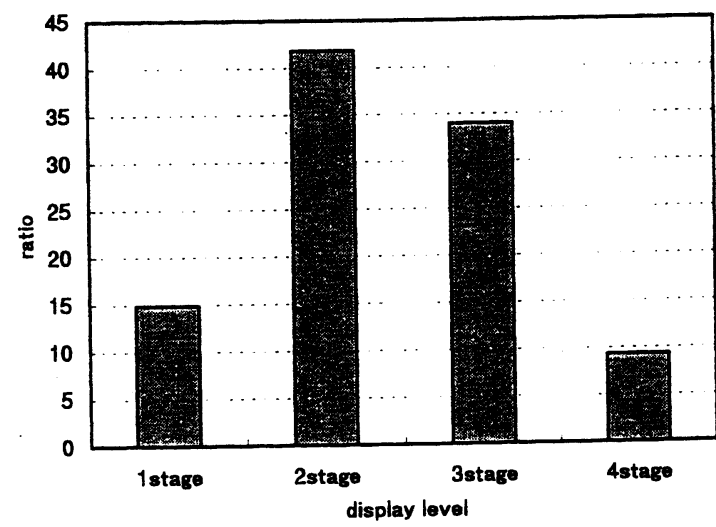

Figure 1 The attention level

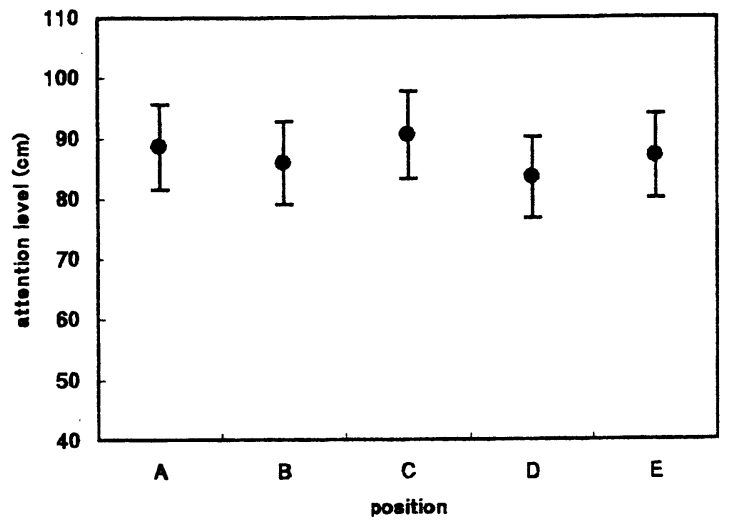

Figure 2 The attention point levels based on differences in position.

\section{Conclusions}

1) We identified through examples the relationships between factors that influence salability.

2) The placement and in-store customer attention distribution for products with high salability are consistent with the hypothesis that height (with respect to eye level) is a factor in salability.

3) Attention frequency influences purchasing decisions.

\section{References}

T. Konosu, Y. Kitahara, and T. Hukuda : A Consideration on the Consumer Buying Behavior by Analyzing the Eye Movement, The Japanese Journal of Ergonomics Vol.31, 206-207, 1995. 